\title{
A rare case of gartner duct cyst presenting as a genital prolapse: a case report
}

\author{
Tanu Bhati*, Sunil Takiar, Kalpana Verma, Kalpna Kulshrestha
}

Department of Obstetrics and Gynecology, SIMS, Hapur, Uttar Pradesh, India

Received: 02 May 2019

Revised: 26 June 2019

Accepted: 09 July 2019

\section{*Correspondence:}

Dr. Tanu Bhati,

E-mail: mili.bhati72@gmail.com

Copyright: () the author(s), publisher and licensee Medip Academy. This is an open-access article distributed under the terms of the Creative Commons Attribution Non-Commercial License, which permits unrestricted non-commercial use, distribution, and reproduction in any medium, provided the original work is properly cited.

\begin{abstract}
Mullerian cysts are usually small, ranging from 0.1 to $2 \mathrm{~cm}$ in diameter. Rarely, they may be enlarged and mistaken for other structures such as uterovaginal prolapse/cystocele/rectocele or urethral diverticulum. Posterior vaginal wall cyst is a very rare case. We present a case of patient presenting with mass coming out from vagina, which, after clinical evaluation and USG, was diagnosed as a Gartner's cyst. Gartner's duct cyst is a derivative of Wolffian duct (mesonephric duct) in females. Assessment of the lesion via history taking and pelvic examination is important to confirm both the lesion's size and location, but appropriate clinical evaluation supported with investigations clinched the diagnosis easily.
\end{abstract}

Keywords: Gartner's duct cyst, Mesonephric duct, Wolffian duct, Vaginal mass

\section{INTRODUCTION}

A Gartner's duct cyst is a benign vaginal cyst that originates from the Gartner's duct which is a vestigial remnant of the mesonephric duct (wolffian duct) in females. ${ }^{1,2}$ They are typically small asymptomatic cysts that occur along the lateral walls of vagina, following the course of the duct. In rare instances, they can be congenital. ${ }^{3-6}$ Gartner cysts account for $11 \%$ of all vaginal cysts and they are the result of total or partial obstruction of the Gartner duct (mesonephric remainder). They are generally located in the anterior or lateral wall of the vagina from the cervix to introitus, although they have exceptionally been described in a posterior location. ${ }^{7}$ Vaginal cyst can be histologically classified as epithelial, inclusion, mullerian, mesonephric and urothelial in addition to other rare types. ${ }^{8}$ These present with symptoms of visible palpable mass, dyspareunia, voiding disturbances, vaginal discharge and pain. ${ }^{9}$ Simple mesonephric (Gartner's) or paramesonephric (Mullerian) cysts may occur at especially high levels near the fornixes. Gartner's duct cysts can also be associated with abnormalities of the metanephric urinary system such as an ectopic ureter, unilateral renal agenesis and renal hypoplasia. Imaging by ultrasound or magnetic resonance imaging (MRI) is essential to identify the exact location of a cyst, the borders thereof, and the extent of communication with the adjacent organs and the urinary tract. Occasionally, a Mullerian cyst may become sufficiently large so that the symptoms warrant excision.

\section{CASE REPORT}

A 23 years old female, married for about 5 years, presented to our department with complaints of an asymptomatic vaginal mass coming out from vagina. She had been elsewhere diagnosed as a Cystocele. There was no history of any surgery for the lesion. General clinical examination was essentially within normal limits. She 
was HbsAg positive. Pelvic examination showed a normal urethra, vaginal and anal openings. A cystic mass, approx $5 \times 3 \mathrm{~cm}$ in size, arising from right lateral vaginal wall could be seen and was confirmed on palpation. Pelvic ultrasound was normal.

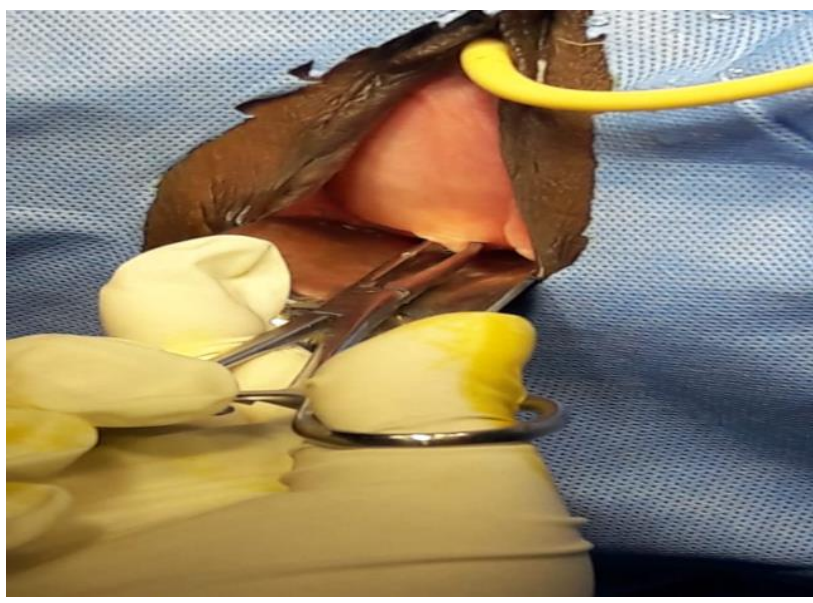

Figure 1: Foley's catheterization in situ, cyst arising from right lateral vaginal wall.

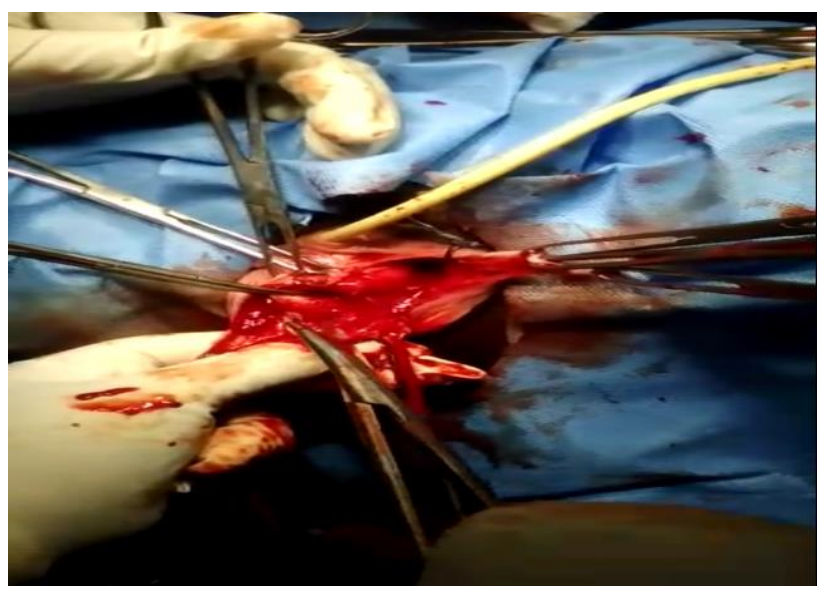

Figure 2: Excision of right lateral vaginal wall from fourchette to the base of cyst.

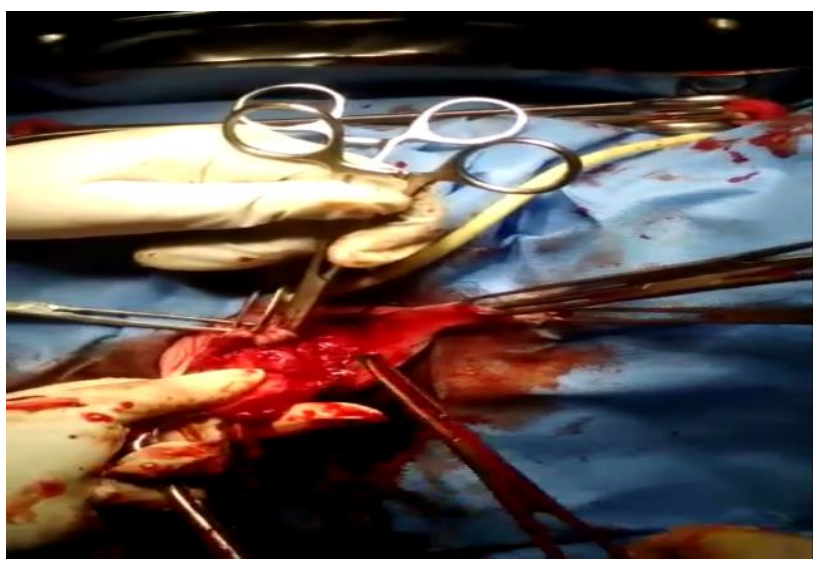

Figure 3: Cyst excision from base of vaginal wall.
All routine blood investigations were within normal limits. An elliptical vaginal wall incision was given over the cyst and the cyst was excised from vaginal wall and underlying tissues (requiring major dissection). There was no connection between cyst and urethra. Vagina could be sutured satisfactorily. Postoperative period was uneventful. Histopathological report of the cyst revealed non mucin secreting cuboidal epithelium in cyst wall.

\section{DISCUSSION}

Gartner duct cyst is a remnant of wolffian duct (mesonephric duct). Its incidence is $11 \%$ of all vaginal cysts. During fetal development, it develops as a result of incomplete regression of mesonephric or wolffian duct. It is usually solitary, but may be multiple. These cysts are usually small and asymptomatic; however giant cysts have also been reported, this one being $5 \times 3 \mathrm{~cm}$ in size. The fluid within cyst was white, thick and viscous. They can also enlarge to substantial proportion and be mistaken for urethral diverticulum or cystocele. ${ }^{10}$ In some rare instances, they can be congenital. There is a small association between Gartner duct cyst and metanephric urinary anomalies such as ectopic ureter and ipsilateral renal hypoplasia. ${ }^{11}$

\section{CONCLUSION}

Gartner's duct cysts are benign vaginal cyst that originates from Gartner's duct, which is a vestigial remnant of mesonephric duct (wolffian duct) in females. These develop as a result of incomplete regression of mesonephric or wolffian duct during fetal development.

\section{Funding: No funding sources \\ Conflict of interest: None declared \\ Ethical approval: Not required}

\section{REFERENCES}

1. Hoogendam JP, Smink M. Gartner Duct Cyst. NE JM. 2017;376(14):e27.

2. Tiwari C, Shah H, Desale J, Waghmare M. 'Neonatal Gartner Duct Cyst: two case reports and literature review. Develop Period Med. 2017;21(1):35-7.

3. Eliber KS, Raz S. Benign cystic lesions of the vagina: A literature review. J Urol. 2003;170(3)71722.

4. Shimizu, Masaki, Imai, Toshihiro. Vaginal cyst in a newborn. J Pediat. 2013;163(6):1790.

5. Merlob P, Bahari C, Liban E, Reisner SH. Cysts of the female external genitalia in the newborn infant. Am J Obstet Gynecol. 1978;132(6):607-10.

6. Heller, Debra S. Vaginal cysts. J Lower Genital Tract Dis. 2012;16(2):140-4.

7. Pradhan S, Ibbon H. Vaginal cysts: a clinicopathological study of 41 cases. Int J Gynecol Pathol. 1986;5:35-46.

8. Sahnidt WN. Pathology of vagina-vaginal cyst. In: Fox H, Wella M, editors. Haines and Taylor 
Obstetrical and Gynaecological Pathology. $5^{\text {th }}$ ed. New York: Churchill Livingstone; 2003:180.

9. Rashmi, Suneja A, Agarwal N, Guleria K, Yadav P. Vaginal mullerian cyst presenting as enterocele. J Obstet Gynaecol India. 2009;59:74-6.

10. Arumugam A, Kumar G, Si, L, Vijayananthan A. Gartner duct cyst in pregnancy presenting as a prolapsing pelvic mass. Biomed Imag Intervent $\mathrm{J}$. 2007:PMID21614298.
11. Currarino G. Single vaginal ectopic ureter and Gartner's duct cyst with ipsilateral renal hypoplasia and dysplasia (or agenesis). J Urol. 1982;128(5):98893.

Cite this article as: Bhati $\mathrm{T}$, Takiar $\mathrm{S}$, Verma $\mathrm{K}$, Kulshrestha K. A rare case of gartner duct cyst presenting as a genital prolapse: a case report. Int $\mathbf{J}$ Reprod Contracept Obstet Gynecol 2019;8:3395-7. 